\title{
CULTURA DE SEGURANÇA DO PACIENTE EM HOSPITAIS: UMA REVISÃO INTEGRATIVA DA LITERATURA
}

\author{
Alexssandro da Silva \\ adm.alexssandro@gmail.com \\ Paulo Roberto Borges de Souza Júnior \\ pborges1@gmail.com \\ Ana Luiza Braz Pavão \\ analuizabp@gmail.com \\ Garibaldi Dantas Gurgel Júnior \\ garibaldi.gurgel@hotmail.com \\ James Anthony Falk \\ thefalks@ terra.com.br
}

\begin{abstract}
Resumo
Este estudo tem como OBJETIVO descrever as principais publicações referentes à cultura de segurança do paciente em hospitais, buscando um melhor entendimento das pesquisas que utilizam o Hospital Survey on Patient Safety Culture (HSOPSC). MÉTODO: Trata-se de uma pesquisa bibliográfica do tipo revisão integrativa da literatura, estruturada em seis etapas que inicia na identificação do tema e seleção da hipótese ou questão de pesquisa para a elaboração da revisão integrativa e finaliza com a apresentação da revisão/síntese do conhecimento. RESULTADOS: após aplicação da equação de busca na base Medline, o HSOPSC foi utilizado como instrumento de avaliação da cultura de segurança do paciente em 94,8\% das publicações. Os EUA, país de origem do HSOPSC, encabeça a lista com $56(30,4 \%$ de $n=184)$ publicações, seguido pelo Irã (13). O Brasil, com oito publicações $(4,3 \%)$, ocupou juntamente com a China a $5^{a}$ posição desta lista. CONCLUSÃO: observa que as publicações referentes à cultura de segurança do paciente têm aumentado muito na literatura internacional e o Brasil acompanha essa tendência de crescimento, tendo seu pico em 2013, coincidindo com o ano de publicação da Resolução da Diretoria Colegiada RDC No 36/ANVISA, que institui ações para a segurança do paciente em serviços de saúde.
\end{abstract}

Palavras-chave: Segurança do Paciente. Gestão da Segurança. Gestão de Riscos. Qualidade da Assistência à Saúde.

\section{PATIENT SAFETY CULTURE IN HOSPITALS: AN INTEGRATIVE LITERATURE REVIEW}

\begin{abstract}
This study aims to OBJECTIVE to describe the main publications on patient safety culture in hospitals, seeking a better understanding of research using the Hospital Survey on Patient Safety Culture (HSOPSC). METHOD: It is a bibliographic research of the integrative literature review type, structured in six steps that begins in the identification of the theme and selection of the hypothesis or research question for the elaboration of the integrative review and ends with the presentation of the review/synthesis of knowledge. RESULTS: After applying the Medline search equation, the HSOPSC was used as an instrument to assess patient safety culture in $94.8 \%$ of the publications. The US, HSOPSC's home country, tops the list with $56(30.4 \%$ of $\mathrm{n}=184)$ publications, followed by Iran (13). Brazil, together with China, ranked 5th on this list with eight publications each (4.3\%). CONCLUSION: The literature review suggests that worldwide publications on patient safety culture have increased over time and Brazil follows the world growth trend, peaking in 2013, coinciding with the year of publication of the Resolution RDC Collegiate Board No. 36/ANVISA which institutes actions for patient safety in health services.
\end{abstract}

Keywords: Patient Safety. Safety Culture. Hospital Survey. Risk Management. Health Care Quality.

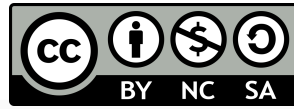

P2P \& INOVAÇÃO, Rio de Janeiro, v. 6 n. 1, Ed. Especial, p.193-211, 2019. 


\section{INTRODUÇÃO}

A alta incidência de Eventos Adversos (EA) em hospitais vem preocupando estudiosos, profissionais e gestores em saúde. Estudos recentes apontam que cerca de 10\% dos pacientes internados sofrem algum tipo de EA, o que torna relevante a sua discussão no contexto da qualidade do cuidado em serviços de saúde (MENDES JÚNIOR et al., 2008).

No contexto dos cuidados de serviços de saúde, a avaliação de qualquer medida do resultado consiste em determinar a extensão em que as diferenças observadas podem ser atribuídas a fatores de risco do paciente ou a variações no processo de tratamento. Isso destaca a importância de medir as diferenças na gravidade dos casos em estudos sobre eventos adversos (MARTINS et al., 2011), da necessidade de identificação das causas mais comuns, importantes etapas adotadas por vários países para chamar a atenção para a gravidade do problema pouco conhecido, e para orientar o desenvolvimento de políticas para a segurança do paciente (MENDES JÚNIOR et al., 2009).

Considerada como uma dimensão da qualidade para os cuidados de saúde, a fim de evitar danos aos pacientes (INSTITUTE OF MEDICINE, 2001), a segurança do paciente é definida como a redução, a um mínimo aceitável, do risco de dano desnecessário associado ao cuidado de saúde (WORLD HEALTH ORGANIZATION, 2009). A segurança do paciente deve passar a fazer parte da cultura da organização e deve estar inserida na filosofia, nas práticas e nos processos de negócio da organização, em vez de ser vista ou praticada como uma atividade em separado (CENTRO DA QUALIDADE, SEGURANÇA E PRODUTIVIDADE PARA O BRASIL E AMÉRICA LATINA, 2004).

A cultura de segurança do paciente é marcada pela comunicação aberta, trabalho em equipe, reconhecimento da dependência mútua e a primazia da segurança como uma prioridade em todos os níveis da organização (WORLD HEALTH ORGANIZATION, 2009). É considerada um importante componente estrutural dos serviços que favorece a implantação de práticas seguras e diminuição de incidentes de segurança (ANDRADE et al., 2018).

Nesse contexto, descrever as principais publicações referentes à avaliação da cultura de segurança do paciente em hospitais apresenta-se como principal objetivo deste estudo, buscando um melhor entendimento das pesquisas que utilizam o Hospital Survey on Patient Safety Culture (HSOPSC).

O HSOPSC é um questionário delineado com a finalidade de mensurar múltiplas dimensões da cultura de segurança do paciente, sendo utilizado atualmente por muitos países (SMITS et al., 2008). Ele questiona a opinião de seus respondentes sobre pontos-chave 
relacionados à segurança - valores, crenças e normas da organização, relato de eventos adversos, comunicação, liderança e gestão, agrupando essas questões em 12 dimensões: (1) Percepção geral da segurança do paciente; (2) Frequência de relato de eventos; (3) Expectativas do supervisor/chefe e ações promotoras da segurança; (4) Aprendizado organizacional melhoria contínua; (5) Trabalho em equipe dentro das unidades; (6) Abertura da comunicação; (7) Retorno da informação e comunicação sobre erro; (8) Respostas não punitivas aos erros; (9) Adequação de profissionais; (10) Apoio da gestão hospitalar para segurança do paciente; (11) Trabalho em equipe entre as unidades; e (12) Passagem de plantão/turno e transferências (REIS, 2013).

A versão original do HSOPSC foi desenvolvida e disponibilizada pela Agency Healthcare Research and Quality (AHRQ) dos EUA, desde 2004. Estudos de validação psicométrica foram surgindo em vários países. A versão brasileira teve sua tradução e adaptação transcultural para a Língua Portuguesa e contexto brasileiro em 2013 (REIS, 2013).

\section{METODO}

Trata-se de uma pesquisa bibliográfica do tipo revisão integrativa da literatura que foi estruturada em seis etapas: (1) identificação do tema e seleção da hipótese ou questão de pesquisa para a elaboração da revisão integrativa; (2) estabelecimento de critérios para inclusão e exclusão de estudos/amostragem ou busca na literatura; (3) definição das informações a serem extraídas dos estudos selecionados/categorização dos estudos; (4) avaliação dos estudos incluídos na revisão integrativa; (5) interpretação dos resultados; e (6) apresentação da revisão/síntese do conhecimento (MENDES; SILVEIRA; GALVÃO, 2008). As duas últimas serão apresentadas na seção de Resultados do presente artigo.

\section{ETAPA 1 - IDENTIFICAÇÃO DO TEMA E SELEÇÃO DA HIPÓTESE OU QUESTÃO DE PESQUISA PARA A ELABORAÇÃO DA REVISÃO INTEGRATIVA}

Segundo Galvão e Pereira (2014), uma boa pergunta de pesquisa analítica, a que investiga a relação entre dois eventos, é formada por diversos componentes que formam o acrônimo PICOS: população; intervenção (ou exposição); comparação; desfecho (O, outcome, do inglês); e tipo de estudo (S, study type, do inglês). Nesse sentido, a tabela 1 apresenta a aplicação do acrônimo PICOS para elaborar a pergunta condutora que utilizamos para iniciar a sistematização das publicações referentes à cultura de segurança do paciente em hospitais. 
Tabela 1 - Componentes da pergunta de pesquisa, seguindo-se o acrônimo PICOS

\begin{tabular}{|c|c|c|}
\hline Descrição & Abreviação & Componentes da pergunta \\
\hline População & $\mathrm{P}$ & $\begin{array}{l}\text { Profissionais de saúde (médico, enfermeiros, técnicos e } \\
\text { auxiliares de enfermagem).. }\end{array}$ \\
\hline Intervenção & I & $\begin{array}{l}\text { Utilização do instrumento HSOPSC em hospitais para } \\
\text { avaliar a cultura de segurança do paciente. }\end{array}$ \\
\hline Comparação & $\mathrm{C}$ & Comparando diferentes estudos. \\
\hline Desfecho & 0 & $\begin{array}{l}\text { Avaliação da cultura de segurança do paciente e suas } \\
\text { dimensões. }\end{array}$ \\
\hline Tipo de estudo & $\mathrm{S}$ & Estudos observacionais descritivos. \\
\hline
\end{tabular}

Fonte: Dados de Pesquisa, 2019

Após a aplicação do acrônimo, chegamos a seguinte pergunta de pesquisa: Como está a cultura de segurança do paciente em hospitais avaliada por meio do Instrumento HSOPSC entre os anos 2000 e 2017 ?

Inicialmente, foi acessada a base Medline com as palavras: "patient safety" AND "safety culture" com o filtro para estudos do tipo Review de 2000 a 2016, a fim de quantificar as repetições de palavras chaves dos artigos de revisão sistemática alinhada à pergunta condutora da pesquisa de publicações.

Após aplicação dos filtros, foi gerado o download do arquivo do tipo .nbib com nome: citations.nbib. Este arquivo foi aberto no formato bloco de notas, do tipo .txt e copiado no Microsoft Excel, a fim de aplicar os filtros e quantificar as palavras.

De forma geral, passamos a utilizar as palavras-chave "patient safety" $e$ "safety culture" nas pesquisas. Entretanto, para delimitar a pesquisa aos critérios de inclusão e exclusão, acrescentamos na equação de busca para base de dados Medline as palavras "hospital survey", "patient safety culture" e "patient safety climate", conforme abaixo:

((patient safety culture[Title/Abstract] OR (patient safety[Title/Abstract] AND safety culture[Title/Abstract])) OR patient safety climate[Title/Abstract]) AND hospital survey[Title/Abstract] AND ("2000/01/01"[PDAT] : "2017/12/31"[PDAT]) 


\section{ETAPA 2 - ESTABELECIMENTO DE CRITÉRIOS PARA INCLUSÃO E EXCLUSÃO DE ESTUDOS/ AMOSTRAGEM OU BUSCA NA LITERATURA}

Foram estabelecidos os seguintes critérios para delimitar a pesquisa:

\section{Critérios de inclusão}

- Artigos publicados que utilizam o instrumento HSOPSC para medição da cultura de segurança do paciente em hospitais;

- Estudos Publicados em língua inglesa, espanhola, portuguesa e francesa;

- Estudos que envolvessem todo hospital;

- Artigos publicados entre os anos de 2000 e 2017;

- Artigos disponibilizados gratuitamente ou por meio de bibliotecas públicas, através de contratos ou pelos próprios autores (ResearchGate, Email ou outros), quando solicitado.

\section{Critérios de exclusão}

- Estudos que utilizassem outros instrumentos diferentes do HSOPSC;

- Estudos realizados em unidades de atenção primária, em casas de cuidado e em atenção domiciliar;

- Estudos que envolvessem pesquisas com o paciente;

- Estudos que não analisaram todas as 12 dimensões do HSOPSC;

- Apresentações em congressos, estudos de caso, estudos qualitativos e estudos intervencionais;

- Estudos realizados em unidades/serviços hospitalares específicas(os), sem envolver o hospital como um todo.

\section{ETAPA 3 - DEFINIÇÃO DAS INFORMAÇÕES A SEREM EXTRAÍDAS DOS ESTUDOS SELECIONADOS/ CATEGORIZAÇÃO DOS ESTUDOS}

Nessa etapa foi definida a metodologia de como seriam selecionados e catalogados os artigos para compor o estudo e quais as informações mais pertinentes para incluir na pesquisa sobre cultura de segurança do paciente.

Todas as referências encontradas de acordo com a equação de busca delimitada aos critérios de inclusão e exclusão tiveram seus resumos baixados para leitura prévia. Nesta etapa, não era nossa intenção refinar a pesquisa com alta sensibilidade aos critérios de inclusão e 


\section{- INOVAÇão}

exclusão, mas catalogar todas as publicações encontradas por meio de planilha Excel, registrando as seguintes informações:

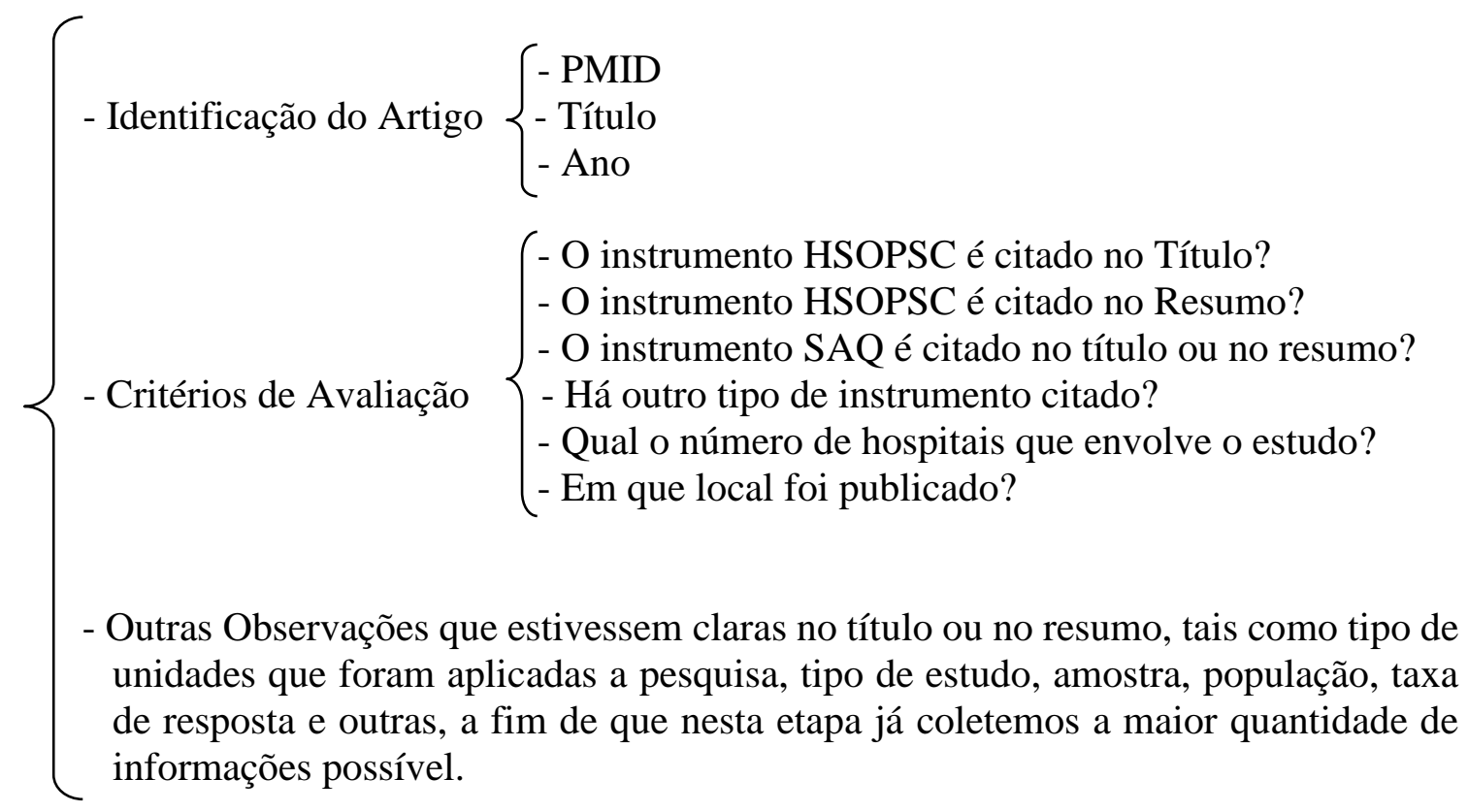

Após o registro dos dados encontrados nos títulos e resumos, aplicamos os filtros de acordo com os critérios de inclusão e exclusão para identificação dos artigos que seriam selecionados para leitura prévia do texto. No caso de dúvida, tendo em vista o artigo não possuir todas as informações registradas na planilha, optamos, mesmo assim, por realizar a sua leitura prévia. A seleção dos artigos para leitura prévia do texto, caracteriza-se por uma análise das informações registradas em planilha e sua respectiva identificação para sinalizar da necessidade de leitura do texto completo na mesma planilha de informações.

Para acessar o artigo selecionado utilizamos os seguintes passos:

$$
\left\{\begin{array}{l}
\text { - Pesquisa por PMID no PubMed/Medline com acesso em rede da biblioteca; } \\
\text { - Pesquisa dos artigos não encontrados por título no Google; } \\
\text { - Solicitação direta aos autores por meio do ResearchGate ou Email; } \\
\text { - Verificação junto à biblioteca local para acesso por meio de outras bibliotecas. }
\end{array}\right.
$$

\section{ETAPA 4 - AVALIAÇÃO DOS ESTUDOS INCLUÍDOS NA REVISÃO INTEGRATIVA}

Os artigos selecionados e acessados foram cadastrados e importados para o Mendeley, a fim de garantir o acesso de todos os pesquisadores para otimizar os trabalhos de análises e facilitar as atualizações de situação (artigos lidos, importantes, selecionados, não selecionado e 
outros). O Mendeley é um gerenciador gratuito de referências e uma rede social acadêmica com acesso via Web (https://www.mendeley.com).

Os artigos que atendiam aos critérios de inclusão e não estavam dentro dos critérios de exclusão da pesquisa, foram classificados como 'selecionados' e foram lidos na íntegra. Seus dados foram extraídos para a planilha de análise, a fim de compará-los com os resultados da pesquisa de campo.

Os resultados serão apresentados em gráficos e tabelas, gerados por meio do Microsoft Excel, para sintetizar as principais publicações sobre o tema, sua evolução de 2000 a 2017, no Brasil e em outros países, com destaque para as principais revistas e suas especialidades, e os valores mínimos e máximos das 12 dimensões da avaliação da cultura de segurança do paciente das pesquisas que utilizaram o HSOPSC.

\section{RESULTADOS E DISCUSSÃO}

Dando seguimento à estrutura proposta por Mendes, Silveira e Galvão (2008), para realização de revisão integrativa da literatura, neste tópico apresentaremos as etapas seguintes, a saber: (5) interpretação dos resultados e (6) apresentação da revisão/síntese do conhecimento.

\subsection{PUBLICAÇÕES SOBRE CULTURA DE SEGURANÇA DO PACIENTE}

Aplicando os filtros da equação de busca na base de dados Medline apenas com as palavras-chave "Patient safety" e 'Safety culture", entre os anos de 2000 a 2017, foram encontradas 1127 publicações. Dessas publicações, 75 (6,7\%) foram de revistas brasileiras e, como pode ser observado no gráfico 1, houve uma evolução crescente generalizada a partir do ano de 2008 . 


\section{- INOVAÇÃo}

Gráfico 1 - Evolução das publicações sobre cultura de segurança do paciente no Brasil e em Outros Países, de 2000 a 2017

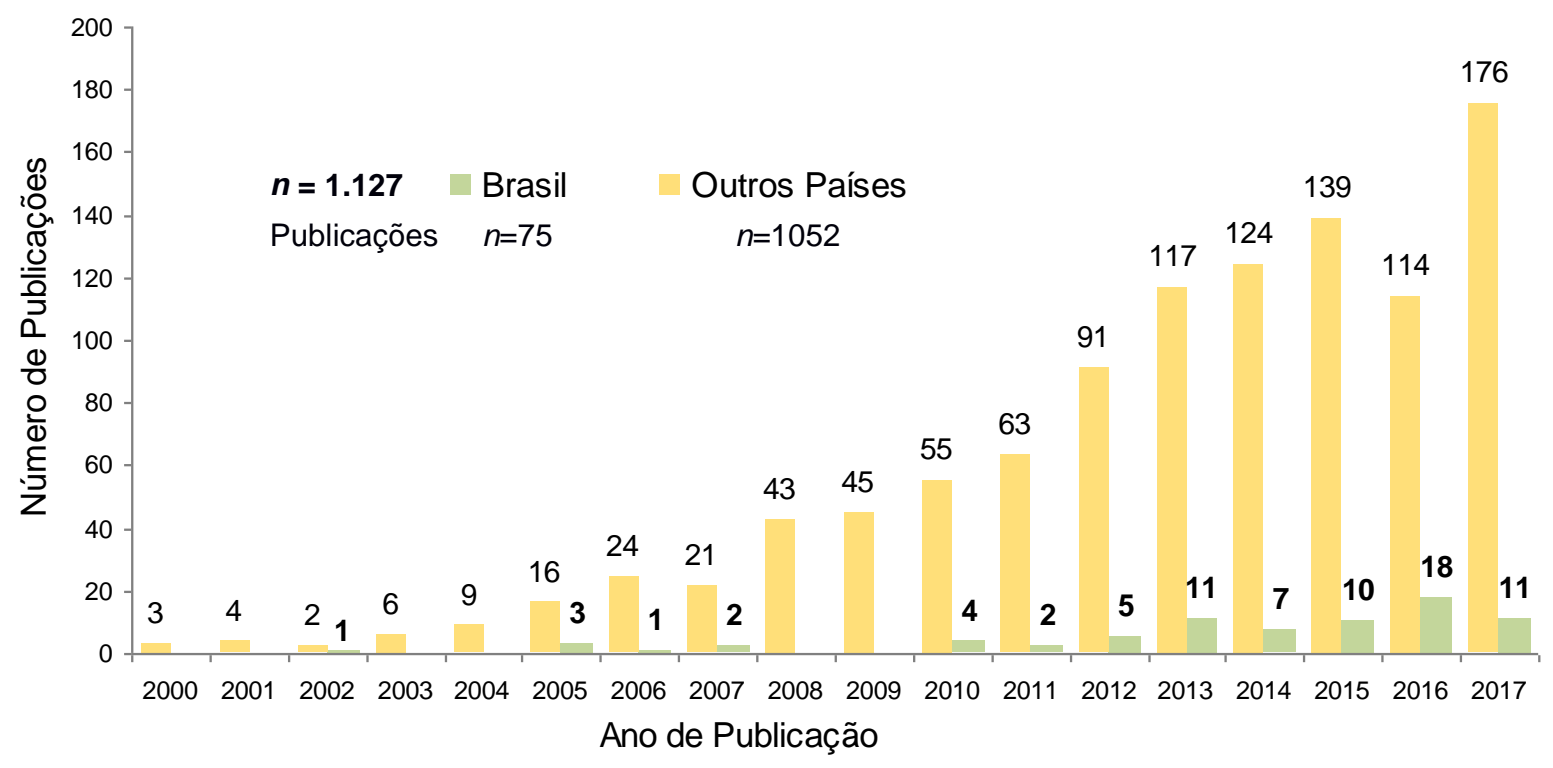

Fonte: Dados de Pesquisa, 2019

No Brasil, a primeira publicação sobre o tema foi no ano de 2002, por meio dos Arquivos Brasileiros de Cardiologia, publicação bimestral da Sociedade Brasileira de Cardiologia. Neste volume, Oliveira Filho et al. (2002), publicaram o artigo com o título 'Reabilitação não Supervisionada: Efeitos de Treinamento Ambulatorial a Longo Prazo'. O estudo teve como objetivo avaliar a segurança e eficácia da reabilitação não supervisionada (RNS), a longo prazo, em pacientes coronários de baixo risco, e teve como conclusão que se trata de uma reabilitação segura e eficaz em pacientes coronários de baixo risco, com benefícios em nível periférico.

A partir de 2005, todos os anos tiveram pelo menos uma publicação no Brasil, exceto nos anos de 2008 e 2009. O primeiro pico no número de publicações no Brasil ocorreu no ano de 2013 que, com 11 publicações, correspondeu a mais de 8,5\% de publicações internacvionais. Provavelmente o número de publicações foi impulsionado pelo advento da Resolução da Diretoria Colegiada - RDC N 36 , publicada pela ANVISA (2013), a qual instituiu ações para a segurança do paciente em serviços de saúde.

De 2013 em diante o Brasil sempre manteve acima de 5\% das publicações mundiais sobre cultura de segurança do paciente, tendo seu ápice no ano de 2016 com 13,6\%, justamente no ano em que os outros paises desaceleraram temporariamente o ritmo de publicações.

Para essas análises, foi considerada apenas a base Medline, tendo em vista indexar o maior número de publicações internacionais. 
O volume de publicações nacionais teve colaboração de várias revistas indexadas, principalmente as revistas especializadas na área de enfermagem - Revista Gaúcha de Enfermagem ( $n=15 \mid 20,0 \%)$, Revista da Escola de Enfermagem da USP ( $n=10 \mid 13,3 \%)$, Revista Latino Americana de Enfermagem (n=8 | 10,7\%) e Revista Brasileira de Enfermagem $(n=7 \mid 9,3 \%)$ - que representaram 53,4\% $(n=40)$ das publicações sobre o tema no Brasil (Gráfico 2).

Gráfico 2 - Publicações sobre cultura de segurança do paciente por Especialidade da Revista e por Revista, no Brasil de 2000 a 2017

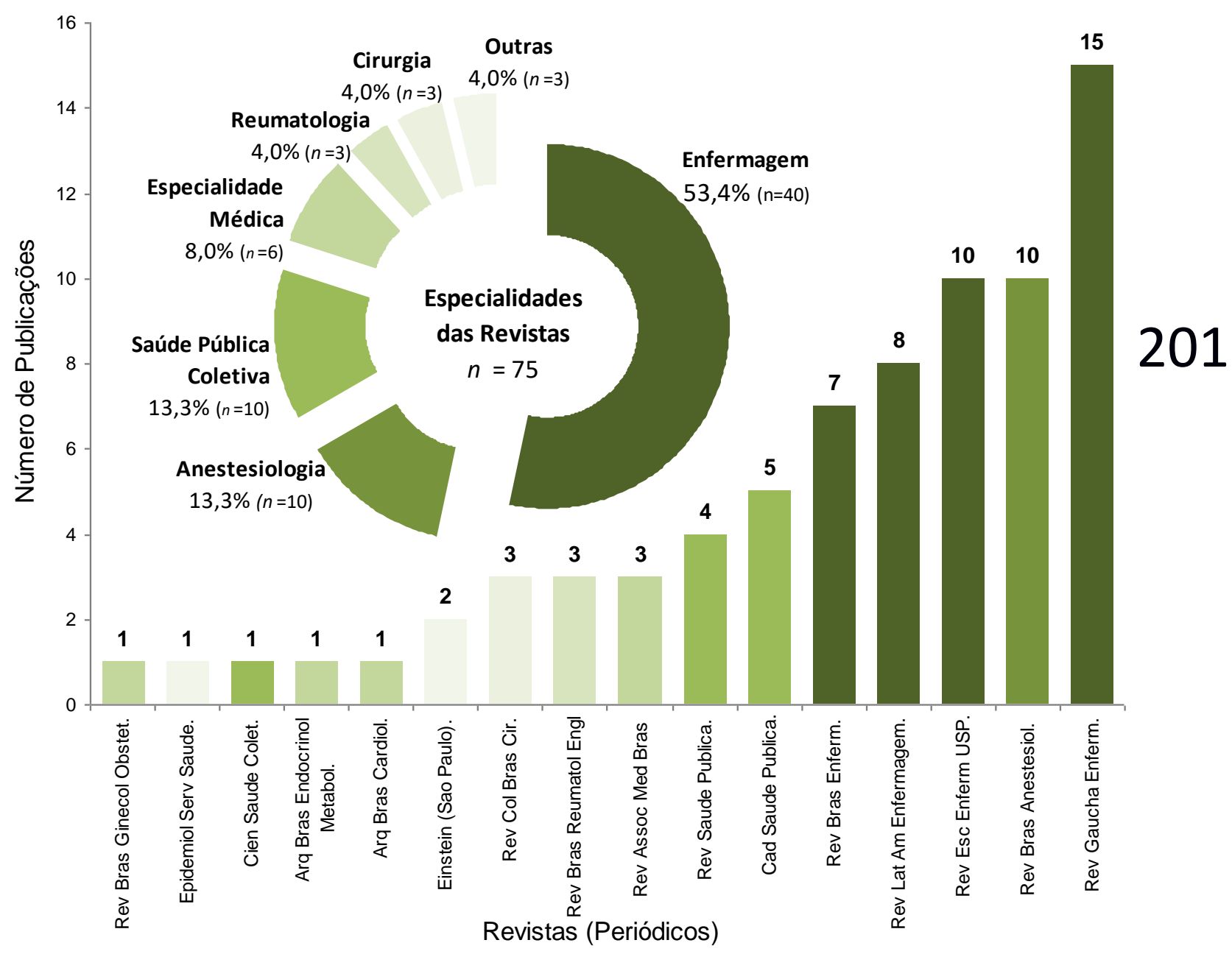

Fonte: Dados de Pesquisa, 2019

Logo em seguida à área de enfermagem, desponta a Revista Brasileira de Anestesiologia que teve 10 publicações no período, correspondendo a mais de $13 \%$ das publicações e com primeira publicação a mais de 12 anos (2005). A Sociedade Brasileira de Anestesiologia, desde 
2014, mantém pelo menos uma publicação sobre o tema em cada ano, chegando até a publicar quatro vezes no mesmo ano.

A área da Saúde Pública e Coletiva também tem se destacado nas publicações sobre segurança do paciente. Três dos seus principais veículos de publicação possuem artigos publicados sobre o tema: Cadernos de Saúde Pública (n=5), Revista de Saúde Pública (n=4) e Ciência \& Saúde Coletiva $(n=1)$. Juntos, esses veículos correspondem a 13,3\% de todas as publicações nacionais e trazem estudos que contribuíram fortemente para alavancar a cultura de segurança do paciente,

Dentre estes estudos, podemos citar quatro deles: três publicados pela Revista Cadernos de Saúde Pública com os artigos de Adaptação transcultural da versão brasileira do Hospital Survey on Patient Safety Culture (REIS; LAGUARDIA; MARTINS, 2012); Indicadores de segurança do paciente para hospitais de pacientes agudos: revisão sistemática (GOUVÊA; TRAVASSOS, 2010); Desenvolvimento e validação de indicadores de boas práticas de segurança do paciente (GAMA et.al., 2016); e um publicado pela Revista de Saúde Pública que apresenta a necessidade de implantar o programa nacional de segurança do paciente no Brasil (CAPUCHO; CASSIANI, 2013).

Vários outros estudos não enfatizados neste trabalho foram publicados por outras revistas que constam no gráfico 1. Um deles, apesar da Revista de Epidemiologia em Serviços de Saúde não ter proeminência na pesquisa feita em publicações desta área, vale o destaque de uma publicação recente da equipe da Universidade Federal do Rio Grande do Norte que apresenta a adaptação e validação do Hospital Survey on Patient Safety Culture em versão brasileira eletrônica (ANDRADE et. al., 2017).

\subsection{PUBLICAÇÕES SOBRE O HOSPITAL SURVEY ON PATIENT SAFETY CULTURE (HSOPSC)}

Após a aplicação da equação de busca completa na base Medline, foi retornado 194. publicações $(n=194)$, segundo critérios da pesquisa para leitura de títulos e resumos. Com a leitura dos resumos foi percebido que o instrumento de avaliação da cultura de segurança do paciente mais utilizado no mundo $(94,8 \%)$ é o Hospital Survey on Patient Safety Culture (HSOPSC) desenvolvido pela Agency Healthcare Research and Quality (AHRQ) dos EUA. Outro instrumento específico sobre cultura do paciente também encontrado na pesquisa foi o Security Attitudes Questionnaire - SAQ (3,6\%), mas na pesquisa sobre sua utilização foi identificado que sempre foi acompanhada do HSOPSC, como pode ser percebida na figura 1 . 
Figura 1 - Esquema de conjunto união e interseção dos instrumentos de pesquisas mais utilizados para avaliar a cultura de segurança do paciente, de 2000 a $2017(n=194)$

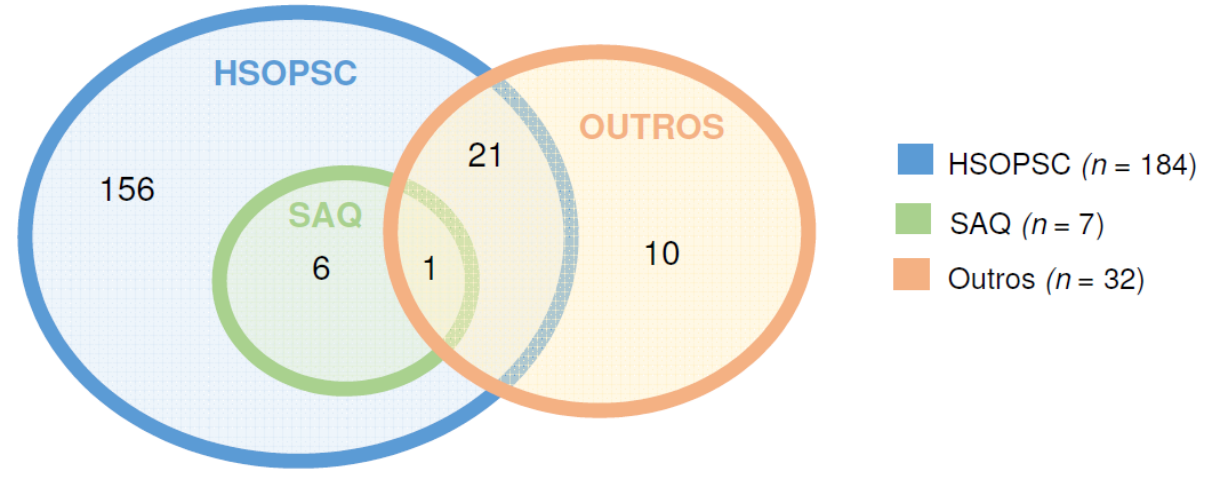

Fonte: Os autores.

Outros instrumentos foram citados nos resumos. Alguns deles foram aplicados em conjunto com o HSOPSC (22), outros não foram percebidos vínculos ligados diretamente com a cultura de segurança do paciente (10).

O gráfico 3 apresenta os países que tiveram mais de uma publicação utilizando o Hospital Survey on Patient Safety Culture (HSOPSC) em suas pesquisas, de 2000 a 2017. Os EUA, país de origem do HSOPSC, encabeça com 56 (30,4\% de $n=184)$ publicações, seguido pelo Irã (13), Espanha (11) e Noruega (9).

Gráfico 3 - Países que tiveram mais de uma publicação utilizando o Hospital Survey on Patient Safety Culture (HSOPSC) em suas pesquisas, de 2000 a 2017

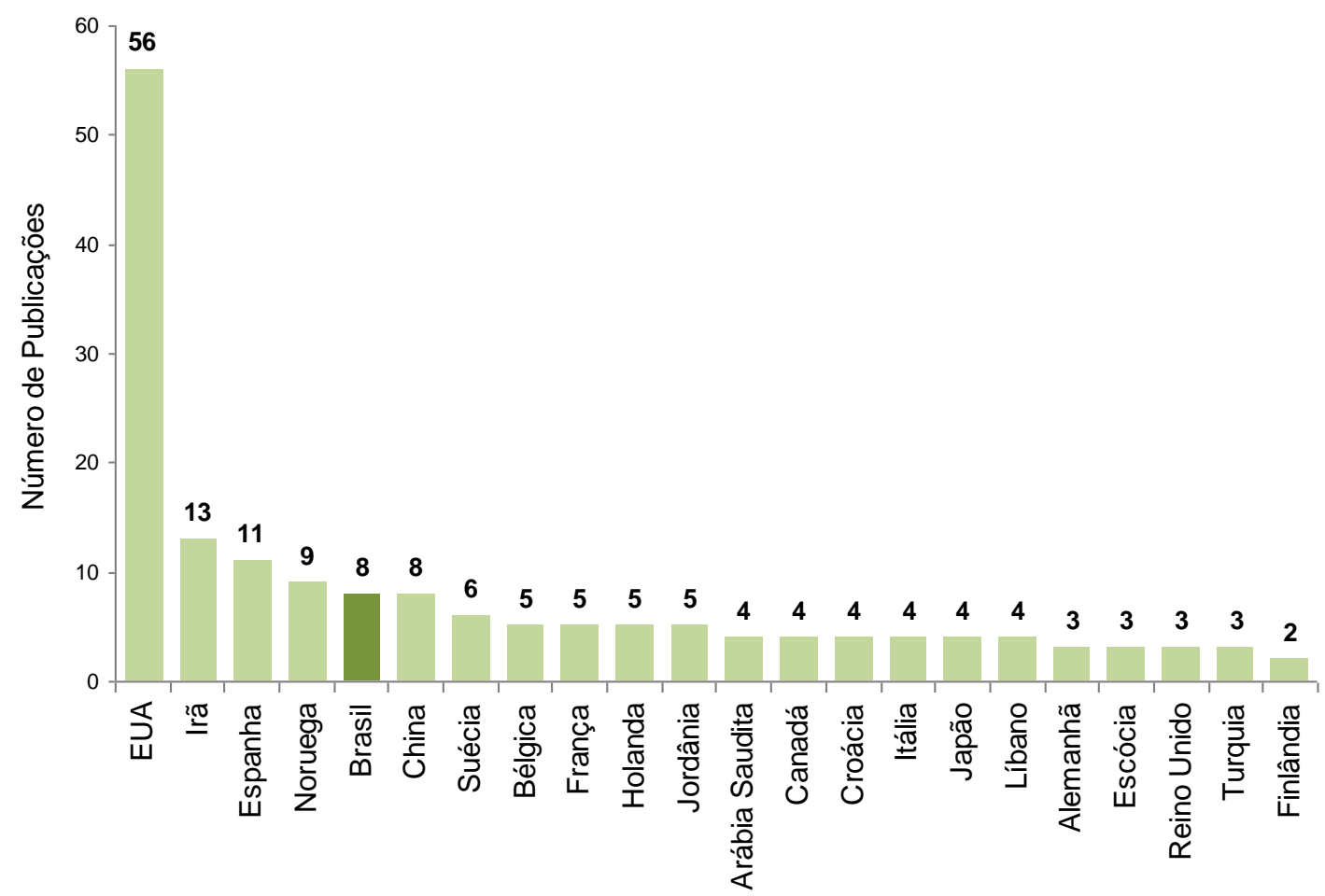

Fonte: Dados de Pesquisa, 2019 
O Brasil, juntamente com a China, com oito publicações cada $(4,3 \%)$, ocupou a $5^{\text {a }}$ posição desta lista. O gráfico 3 apresenta apenas os 22 países que tiveram no mínimo 2 publicações, totalizando 169 (91,8\%) publicações. Outros 15 países tiveram apenas uma publicação (8,2\%) que foram: Amsterdã / Países Baixos, Chipre, Cisjordânia, Egito, Eslovênia, Etiópia, Índia, Irlanda, Macedônia, Nova Zelândia, Omã, Portugal, Suiça, Taiwan e Tunísia.

Como pode ser percebido no gráfico 4, as publicações sobre HSOPSC iniciaram em 2006 e cresceram ao longo do tempo, não necessariamente de forma linear progressiva, porém. Os anos mais recentes tiveram menos publicação que anos antigos, caracterizando um crescimento quase 'serrilhado'. Entretanto, se colocásse uma linha de tendência, ela seria crescente.

Gráfico 4 - Evolução das publicações que utilizaram o Hospital Survey on Patient Safety Culture (HSOPSC) em suas pesquisas, no Brasil e em Outros Países, de 2006 a 2017

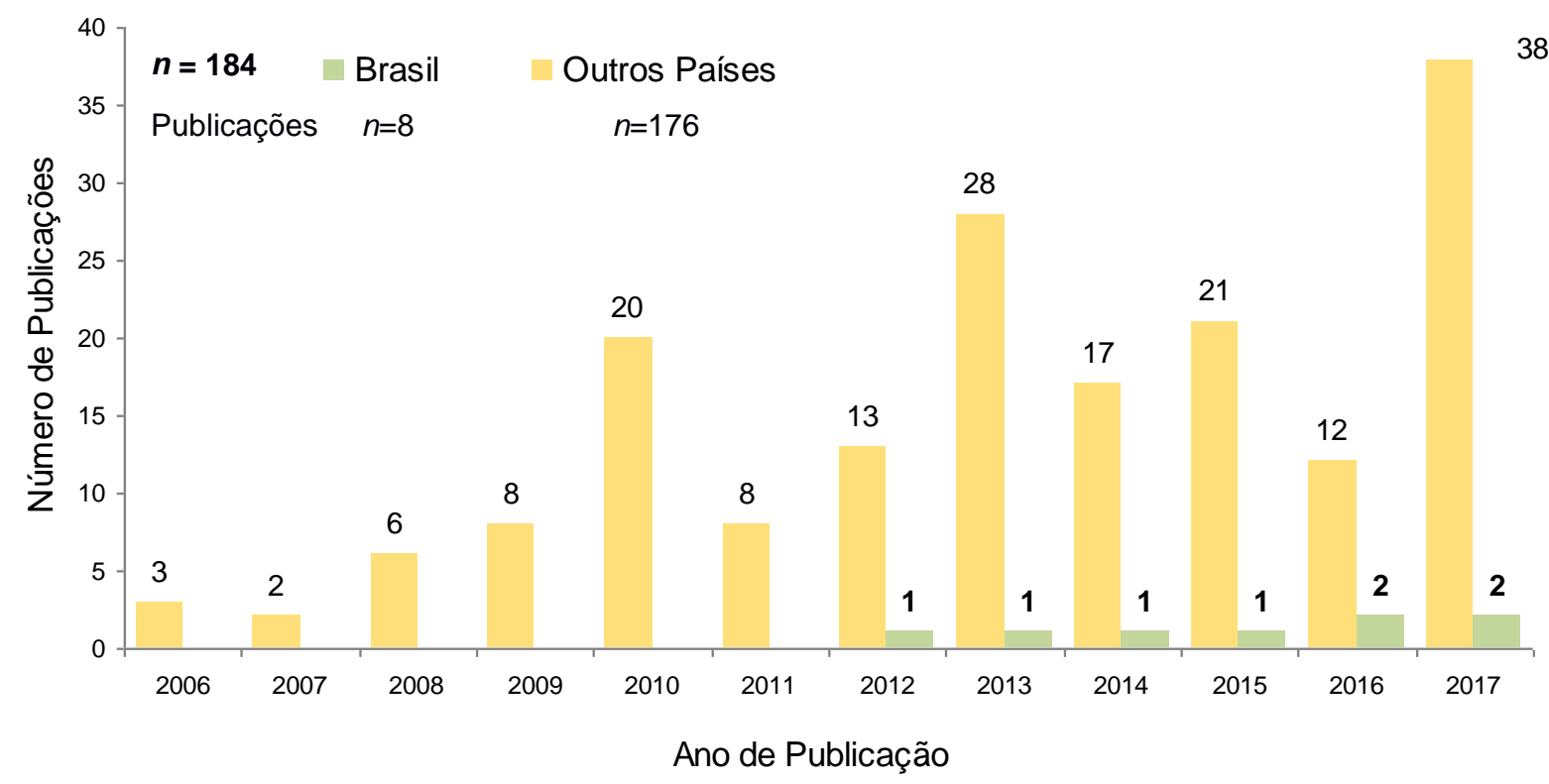

Fonte: Dados de Pesquisa, 2019

Outro ponto que merece destaque são as áreas de especialidades que realizaram pesquisas utilizando o HSOPSC, que pode ser observado no gráfico 5. O destaque para os 'Hospitais' (58,7\%) já era esperado, mas foi seguido pelas seguintes três áreas - UTI (20 estudos) Centro Cirúrgico (9 estudos) e Lares de Idosos (4 estudos), entre outras. 
Gráfico 5 - Principais áreas que utilizaram o Hospital Survey on Patient Safety Culture (HSOPSC) em suas pesquisas, de 2006 a 2017

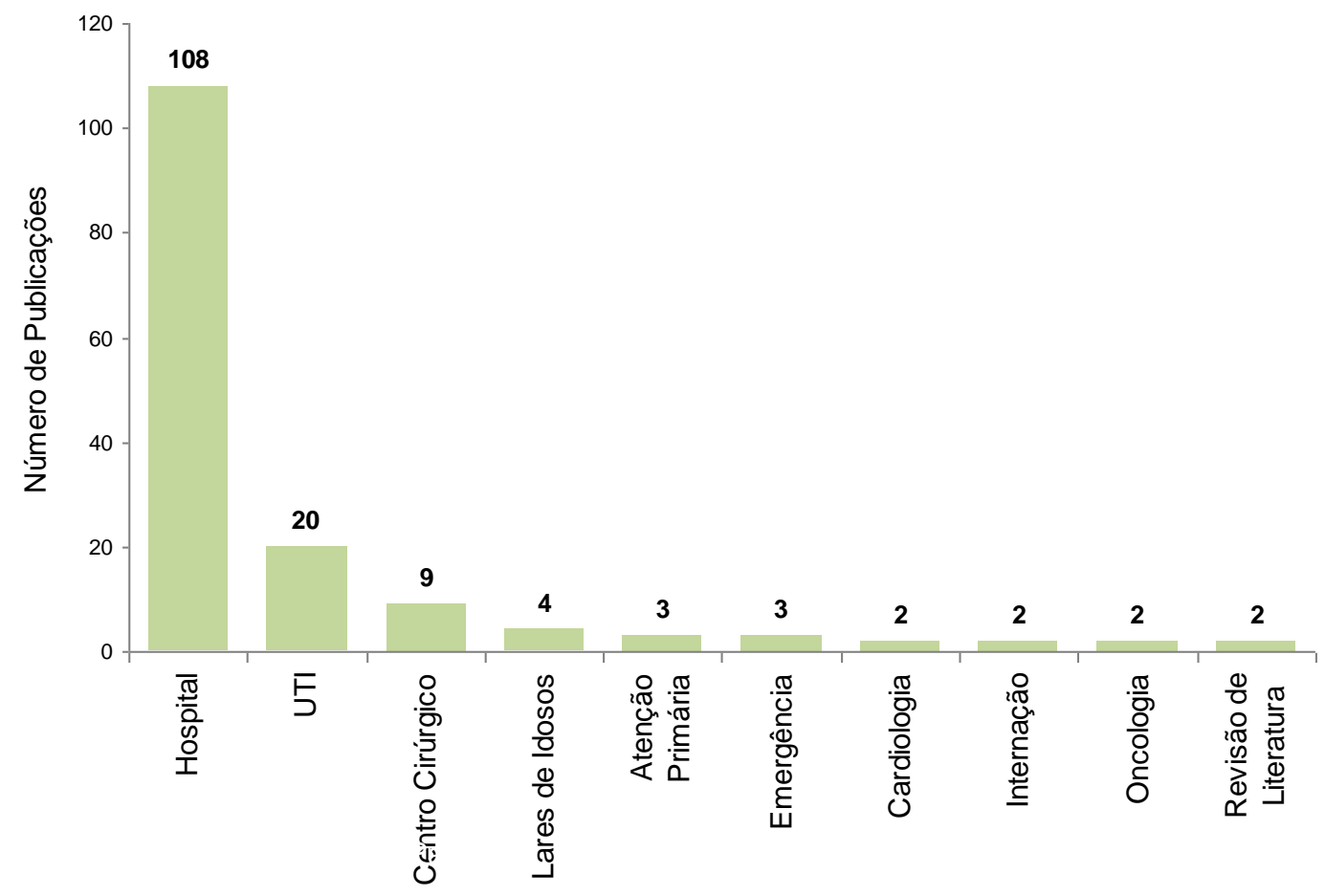

Fonte: Dados de Pesquisa, 2019

Das 184 publicações sobre HSOPSC, houve 155 publicações nas áreas constantes do gráfico 5, e 29 em outras áreas que possuíam apenas uma publicação.

Na tabela 2 são apresentados os resultados obtidos da avaliação da cultura de segurança do paciente publicados em 15 estudos de outros países que utilizaram as seguintes dimensões do HSOPSC: (1) Percepção geral da segurança do paciente; (2) Frequência de relato de eventos; (3) Expectativas do supervisor/chefe e ações promotoras da segurança; (4) Aprendizado organizacional - melhoria contínua; (5) Trabalho em equipe dentro das unidades; (6) Abertura da comunicação; (7) Retorno da informação e comunicação sobre erro; (8) Respostas não punitivas aos erros; (9) Adequação de profissionais; (10) Apoio da gestão hospitalar para segurança do paciente; (11) Trabalho em equipe entre as unidades; e (12) Passagem de plantão/turno e transferências. 
Tabela 2 - Consolidação das proporções com resultado 'positivo' das principais publicações sobre cultura de segurança do paciente que utilizaram o HSOPSC, nos anos 2006 a 2017

\begin{tabular}{|c|c|c|c|c|c|c|c|c|c|c|c|c|c|c|}
\hline \multirow{2}{*}{$\begin{array}{l}\text { Primeiro } \\
\text { Autor }\end{array}$} & \multirow{2}{*}{ Ano } & \multirow{2}{*}{$\begin{array}{c}\text { País } \\
\text { Estudo }\end{array}$} & \multicolumn{12}{|c|}{ Dimensões da Cultura de Segurança do Paciente } \\
\hline & & & 1 & 2 & 3 & 4 & 5 & 6 & 7 & 8 & 9 & 10 & 11 & 12 \\
\hline Wagner C (1) & 013 & Holanda & 49,0 & 36,0 & 63,0 & 47,0 & 85,0 & 68,0 & 52,0 & 66,0 & 59,0 & 31,0 & 28,0 & 42,0 \\
\hline Wagner C (2) & 013 & Taiwan & 52,0 & 31,0 & 65,0 & 80,0 & 81,0 & 40,0 & 44,0 & 31,0 & 40,0 & 60,0 & 56,0 & 43,0 \\
\hline Wagner C (3) & 2013 & EUA & 64,0 & 60,0 & 75,0 & 71,0 & 79,0 & 62,0 & 63,0 & 44,0 & 55,0 & 70,0 & 57,0 & 44,0 \\
\hline Tereanu C & 2017 & Itália & & 48,0 & 58,0 & 51,0 & 59,0 & 65,0 & 43,0 & 40,0 & & 44,0 & 37,0 & 36,0 \\
\hline Chen I Li H (1) & 2010 & $\mathrm{AHRQ}$ & 63,0 & 59,0 & 74,0 & 69,0 & 78,0 & 61,0 & 62,0 & 43,0 & 55,0 & 69,0 & 57,0 & 45,0 \\
\hline Chen I Li H (2) & 2010 & & 65,0 & 57,0 & 83,0 & 84,0 & 94,0 & 58,0 & 59,0 & 45,0 & 39,0 & 62,0 & 72,0 & 48,0 \\
\hline Bagnasco A & 2011 & Itália & 64,0 & 59,0 & 69,0 & 74,0 & 64,0 & 62,0 & 60,0 & 35,0 & 30,0 & 28,0 & 30,0 & 37,0 \\
\hline $\begin{array}{l}\text { A.M. Aboul- } \\
\text { Fotouh }\end{array}$ & 2012 & Egito & 33,9 & 33,4 & 46,4 & 78,2 & 58,1 & 34,6 & 39,7 & 19,5 & 49,3 & 27,2 & 38,0 & 24,6 \\
\hline Hamdan M & 2013 & Cisjordânia & 43,0 & 35,0 & 56,0 & 62,0 & 71,0 & 36,0 & 46,0 & 17,0 & 38,0 & 37,0 & 44,0 & 48,0 \\
\hline Alahmadi $\mathrm{H}$ & 2010 & $\begin{array}{l}\text { Saudita } \\
\text { Arábia }\end{array}$ & 59,0 & 63,0 & 70,0 & 87,0 & 84,0 & 60,0 & 77,0 & 22,0 & 27,0 & 74,0 & 50,0 & 61,0 \\
\hline Al-Awa B & 2012 & $\begin{array}{l}\text { Arábia } \\
\text { Saudita }\end{array}$ & 45,0 & 57,0 & 51,0 & 74,0 & 68,0 & 36,0 & 58,0 & 16,0 & 15,0 & 61,0 & 51,0 & 47,0 \\
\hline $\begin{array}{l}\text { Ghahramanian } \\
\text { A }\end{array}$ & 2017 & Irã & 66,6 & 56,4 & 63,3 & 68,2 & 65,9 & 58,8 & 63,3 & 45,9 & 45,9 & 66,5 & 55,0 & 62,6 \\
\hline Nie Y & 2013 & China & 55,0 & & 63,0 & 88,0 & 84,0 & 65,0 & 50,0 & 60,0 & 45,0 & 69,0 & 66,0 & \\
\hline Moussavi F & 2013 & Irã & 37,0 & 33,0 & 42,0 & 46,0 & 48,0 & 27,0 & 38,0 & 12,0 & 22,0 & 42,0 & 39,0 & 39,0 \\
\hline Agnew C & 2013 & Escócia & 56,0 & 56,0 & 65,0 & 64,0 & 73,0 & 54,0 & 45,0 & 44,0 & 45,0 & 38,0 & 39,0 & 32,0 \\
\hline
\end{tabular}

No gráfico 6, foram incluídos os valores mínimos e máximos dos resultados apresentados na tabela 2 para melhor analisar as dimensões da avaliação da cultura do paciente.

Gráfico 6 - Dimensões da cultura de segurança do paciente consolidadas por proporção, com valores mundiais mínimos e máximos

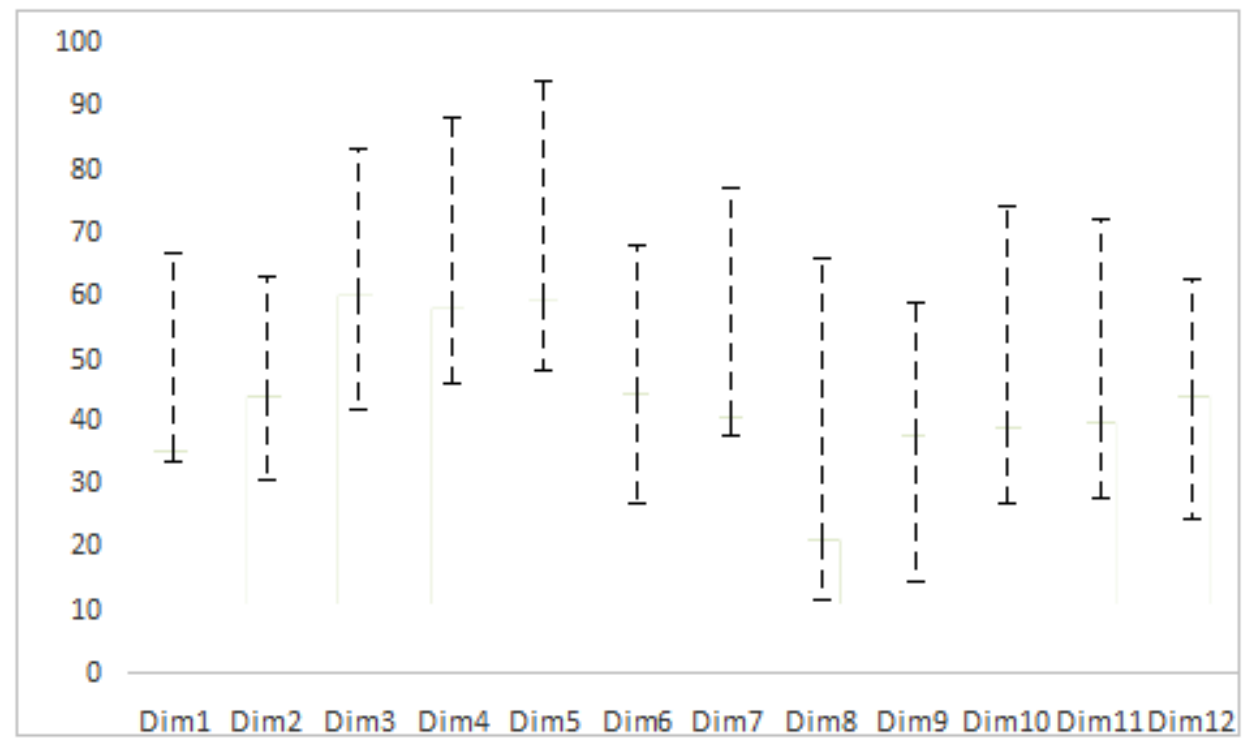

Fonte: Dados de Pesquisa, 2019

A curva das dimensões da cultura de segurança do paciente se comporta de forma semelhante nos países estudados. A dimensão 5 - 'Trabalho em equipe dentro das unidades' obteve o maior resultado positivo, tendo Taiwan como o país com maior valor $(94,0 \%)$. E as 
'Respostas não punitivas aos erros' foi a dimensão (Dim8), que obteve a menor proporção de respostas positivas, principalmente no Irã (12\% positivo) (MOUSSAVI et. al, 2013), o que reflete internacionalmente a preponderância da cultura da culpabilidade nas organizações de saúde (LEAPE et al.,1998). Ao lidar com o erro, uma resposta não punitiva deve ocorrer (GHAHRAMANIAN, 2017), pois é de fundamental importância que a cultura da culpa e do castigo seja substituída pela cultura da aprendizagem a partir da identificação e análise das falhas (QUINTO NETO, 2006).

\section{CONCLUSÃO}

Observa-se que internacionalmente as publicações referentes à cultura de segurança do paciente têm aumentado, não necessariamente de forma linear progressiva, mas com tendência crescente, principalmente as publicações que utilizam o Hospital Survey on Patient Safety Culture (HSOPSC).

No Brasil, as publicações referentes ao tema acompanham a tendência mundial de crescimento, principalmente a partir de 2013, o primeiro pico no número de publicações. Provavelmente isto ocorreu impulsionado pelo advento da Resolução da Diretoria Colegiada RDC $\mathrm{N}^{\mathrm{O}}$ 36, publicada pela ANVISA, que institui ações para a segurança do paciente em serviços de saúde (AGÊNCIA NACIONAL DE VIGILÂNCIA SANITÁRIA, 2013).

A curva das dimensões da cultura de segurança do paciente se comporta de forma semelhante nos países estudados e que a preponderância da cultura da culpabilidade nas organizações de saúde é de fundamental importância que seja substituída pela cultura da aprendizagem.

A melhoria da cultura de segurança tem trazido grande contribuição para o processo de desenvolvimento das organizações de cuidados de saúde, fornecendo uma ampla visão institucional e uma maior confiança dos profissionais.

De forma geral, é notória a necessidade de ampliar a discussão sobre a cultura de segurança hoje internalizada nos hospitais, com o objetivo de adotar intervenções na área de segurança do paciente para reduzir, a um mínimo aceitável, os riscos de danos associados ao cuidado de saúde prestado. 


\section{REFERENCIAS}

AGÊNCIA NACIONAL DE VIGILÂNCIA SANITÁRIA. Resolução da Diretoria Colegiada no 36 de 25 de julho de 2013. Brasília: ANVISA, 2013. Disponível em: http://bvsms.saude.gov.br/bvs/saudelegis/anvisa/2013/rdc0036_25_07_2013.html. Acesso em: 23 nov. 2017.

ABOUL-FOTOUH, A. M. et al. Assessment of patient safety culture among healthcare providers at a teaching hospital in Cairo, Egypt. East. Mediterr. Health J., Cairo, v, 18, n. 4, p. 372-7, abr. 2012. Disponível em:

http://applications.emro.who.int/emhj/v18/04/18_4_2012_0372_0377.pdf. Acesso em: 20 jan. 2017.

AGNEW, C.; FLIN, R.; MEARNS, K. Patient safety climate and worker safety behaviours in acute hospitals in Scotland. J. Safety Res., Nova York, v. 45, p. 95-101, jun. 2013.

Disponível em:

https://www.sciencedirect.com/science/article/pii/S0022437513000091?via\%3Dihub. Acesso em: 20 jan. 2017.

ALAHMADI, H. A. Assessment of patient safety culture in Saudi Arabian hospitals. Qual. Saf. Health Care, London, v. 19, n. 5, p. 1-5, out. 2010. Disponível em:

https://qualitysafety.bmj.com/content/qhc/19/5/e17.full.pdf. Acesso em: 20 jan. 2017.

AL-AWA, B. et al. Benchmarking the post-accreditation patient safety culture at King

Abdulaziz University Hospital. Ann. Saudi. Med., Riyadh, v. 32, n. 2, p. 143-50, mar./abr. 2012. Disponível em: https://www.ncbi.nlm.nih.gov/pmc/articles/PMC6086642/pdf/asm-2143.pdf; Acesso em: 20 jan. 2017.

ANDRADE, L. E. L. et al. Adaptation and validation of the Hospital Survey on Patient Safety Culture in an electronic Brazilian version. Epidemiol. Serv. Saude, Brasília, v. 26, n.3, p. 455-468, jul./set. 2017. Disponível em: http://www.scielo.br/pdf/ress/v26n3/en_2237-9622ress-26-03-00455.pdf. Acesso em 15 jan. 2018.

ANDRADE, L. E. L. et al. Patient safety culture in three Brazilian hospitals with different types of management. Cien. Saude Colet., Rio de Janeiro, v. 23, n. 1, p. 161-172, jan. 2018. Disponível em: http://www.scielo.br/pdf/csc/v23n1/1413-8123-csc-23-01-0161.pdf. Acesso em: 10 mar. 2018.

BAGNASCO, A. et al. Patient safety culture: an Italian experience. J. Clin. Nurs., Oxford, v. 20, n. 7-8, p. 1188-95, abr. 2011. Disponível em:

https://onlinelibrary.wiley.com/doi/pdf/10.1111/j.1365-

2702.2010.03377.x\#accessDenialLayout. Acesso em: 10 ago. 2016.

CAPUCHO, H. C.; CASSIANI, S. H. The need to establish a national patient safety program in Brazil. Rev. Saúde Publica, São Paulo, v. 47, n. 4, 791-8, ago. 2013. Disponível em: http://www.scielo.br/pdf/rsp/v47n4/en_0034-8910-rsp-47-04-0791.pdf. Acesso em 10 ago. 2016 ,

CENTRO DA QUALIDADE, SEGURANÇA E PRODUTIVIDADE PARA O BRASIL E AMÉRICA LATINA. AS/NZS 4360:2004: Gestão de Riscos. 2. ed. São Paulo: Risk Tecnologia, 2004. 
CHEN, I. C.; LI, H. H. Measuring patient safety culture in Taiwan using the Hospital Survey on Patient Safety Culture (HSOPSC). BMC Health Serv. Res., London, v. 10, n. 152, p. 110, jun. 2010. Disponível em:

https://www.ncbi.nlm.nih.gov/pmc/articles/PMC2903582/pdf/1472-6963-10-152.pdf. Acesso em: 10 jan. 2017.

GALVÃO, T. F.; PEREIRA, M. G. Revisões sistemáticas da literatura: passos para sua elaboração. Epidemiol. Serv. Saúde, Brasília, v. 23, n. 1, p. 183-184, jan./mar. 2014. Disponível em: http://www.scielo.br/pdf/ress/v23n1/2237-9622-ress-23-01-00183.pdf. Acesso em: 10 ago. 2016.

GAMA, Z. A. et al. Development and validation of indicators for best patient safety practices: the ISEP-Brazil Project. Cad. Saude Publica, Rio de Janeiro, v. 32, n. 9, p. 1-17, set. 2016. Disponível em: http://www.scielo.br/pdf/csp/v32n9/1678-4464-csp-32-09-e00026215.pdf. Acesso em: 23 mar. 2017.

GOUVÊA, C. S.; TRAVASSOS, C. Patient safety indicators for acute care hospitals: a systematic review. Cad. Saúde Pública, Rio de Janeiro, v. 26, n. 6, p. 1061-78, jun. 2010. Disponível em: http://www.scielo.br/pdf/csp/v26n6/02.pdf. Acesso em: 23 mar. 2017.

GHAHRAMANIAN, A. et al. Quality of healthcare services and its relationship with patient safety culture and nurse-physician professional communication. Health Promot. Perspect., Tabriz, v. 7, n. 3, p. 168-174, jun. 2017, Disponível em: https://www.ncbi.nlm.nih.gov/pmc/articles/PMC5497369/pdf/hpp-7-168.pdf. Acesso em: 12 jan. 2018.

HAMDAN, M.; SALEEM, A. A. Assessment of patient safety culture in Palestinian public hospitals. Int. J. Qual. Health Care, Oxford, v. 25, n. 2, p. 167-75, abr. 2013. Disponível em: https://academic.oup.com/intqhc/article/25/2/167/1855946. Acesso em: 23 mar. 2017.

INSTITUTE OF MEDICINE. Crossing the Quality Chasm: A New Health System for the 21st Century. Washington: National Academy Press, 2001. Disponível em: http://www.nationalacademies.org/hmd/ /media/Files/Report\%20Files/2001/Crossing-theQuality-Chasm/Quality\%20Chasm\%202001\%20\%20report\%20brief.pdf. Acesso em: 20 jan. 2017.

LEAPE, L. L. et al. Promoting patient safety by preventing medical error. JAMA, Chicago, v. 280. p. 1444-1447, 1998. Disponível em: https://jamanetwork.com/journals/jama/articleabstract/188093. Acesso em: 23 mar. 2017.

MARTINS, M. et al. Hospital deaths and adverse events in Brazil. BMC Health Serv. Res., London, v. 11, n. 223, p. 1-8, set. 2011. Disponível em:

https://bmchealthservres.biomedcentral.com/articles/10.1186/1472-6963-11-223. Acesso em: 27 abr. 2017.

MENDES JÚNIOR, W. V. et al. Adaptação dos instrumentos de avaliação de eventos adversos para uso em hospitais brasileiros. Rev. Bras. Epidemiol., São Paulo, v. 11, n. 1, p. 55-66, mar. 2008. Disponível em:

http://www.scielo.br/scielo.php?script=sci_arttext\&pid=S1415-790X2008000100005. Acesso em: 17 jun. 2017. 
MENDES JÚNIOR, W. V. et al. The assessment of adverse events in Brazilian hospitals. Int. J. Qual. Health Care, Oxford, v. 21, p. 279-84, ago. 2009. Disponível em: https://academic.oup.com/intqhc/article/21/4/279/1801452. Acesso em: 13 ago. 2017.

MENDES, K. D. S.; SILVEIRA, R. C. C. P.; GALVÃO, C. M. G. Revisão integrativa: método de pesquisa para a incorporação de evidências na saúde e na enfermagem. Texto contexto enferm., Florianópolis, v. 17, n. 4, out./dez. 2008. Disponível em: http://www.scielo.br/pdf/tce/v17n4/18.pdf. Acesso em 27. abr. 2016.

MOUSSAVI, F. et.al. Assessment of patient safety culture among personnel in the hospitals associated with Islamic Azad University in Tehran in 2013. Electron Physician, Mashhad, v. 5, n, 3, p. 664-71, ago. 2013. Disponível em: https://www.ncbi.nlm.nih.gov/pmc/articles/PMC4477748/pdf/epj-05-664.pdf. Acesso em: 10 jul. 2017.

NIE, Y. et al. Hospital survey on patient safety culture in China. BMC Health Serv. Res., London, v. 13, n. 228, p. 1-11, jun. 2013. Disponível em:

https://www.ncbi.nlm.nih.gov/pmc/articles/PMC3701538/pdf/1472-6963-13-228.pdf. Acesso em: 27 abr. 2017.

OLIVEIRA FILHO, J. A. et al. Unsupervised rehabilitation: effects of exercise training over the long run. Arq. Bras. Cardiol., São Paulo, v. 79, n. 3, p. 233-44, set. 2002. Disponível em: http://www.scielo.br/pdf/abc/v79n3/a04v79n3.pdf. Acesso em: 27 abr. 2017.

QUINTO NETO, A. Segurança dos pacientes, profissionais e organizações: um novo padrão de assistência à saúde. RAS, São Paulo, v. 8, n. 33, p. 153-158, out./dez. 2006. Disponível em: http://www.nascecme.com.br/artigos/RAS33_seguranca.pdf. Acesso em: 22 nov. 2017.

REIS, C. T. A cultura de segurança do paciente: validação de um instrumento de mensuração para o contexto hospitalar brasileiro. 2013. Tese (Doutorado em Saúde Pública) Escola Nacional de Saúde Pública Sérgio Arouca, Fundação Oswaldo Cruz, Rio de Janeiro, 2013. Disponível em: https://www.arca.fiocruz.br/bitstream/icict/14358/1/601.pdf. Acesso em: 18 mar. 2016

REIS, C. T.; LAGUARDIA, J.; MARTINS, M. Adaptação transcultural da versão brasileira do Hospital Survey on Patient Safety Culture: etapa inicial. CSP, Rio de Janeiro, v. 28, n. 11, p.2199-2210, nov. 2012. Disponível em: http://www.scielo.br/pdf/csp/v28n11/19.pdf. Acesso em: 18 mar. 2016

SMITS, M. et al. The psychometric properties of the "Hospital Survey on Patient Safety Culture" in Dutch hospitals. BMC Health Serv. Res, London, v. 8, p. 230-238, nov. 2008. Disponível em: https://www.ncbi.nlm.nih.gov/pmc/articles/PMC2588576/pdf/1472-6963-8230.pdf. Acesso em: 15 nov. 2016

TEREANU, C. et al. Experimenting the hospital survey on patient safety culture in prevention facilities in Italy: psychometric properties. Int. J. Qual. Health Care, Oxford, v. 29, n. 2, p. 269-275, abr. 2017. Disponível em:

https://academic.oup.com/intqhc/article/29/2/269/2996514. Acesso em:

WAGNER, C. et al. Assessing patient safety culture in hospitals across countries. Int. J.

Qual. Health Care, Oxford, v. 25, n. 3, p. 213-21, jul. 2013. Disponível em: 
O INOVAÇÃo

https://www.ncbi.nlm.nih.gov/pmc/articles/PMC3671738/pdf/mzt024.pdf. Acesso em: 21 set. 2016.

WORLD HEALTH ORGANIZATION. Conceptual Framework for the International Classification for Patient Safety: Final Technical Report January 2009. Version 1.1.

Disponível em: https://www.who.int/patientsafety/taxonomy/icps_full_report.pdf. Acesso em: 15 jun. 2016. 